\title{
INFLUÊNCIA DOS PONTOS CARDEAIS E COLATERAIS NA NIDIFICAÇÃO DE ABELHAS NATIVAS EM COLMEIAS OCTOGONAIS
}

\author{
Dayane Cristine de Oliveira Lacerda ${ }^{1 *}$, Italo de Souza Aquino ${ }^{2}$, Péricles de Farias Borges $^{3}$, Alex \\ DA Silva Barbosa ${ }^{2}$
}

\author{
${ }^{1}$ Discente do Doutorado em Sistemas de Produção Agrícola Familiar, Universidade Federal de Pelotas \\ ${ }^{2}$ Docente do Centro de Ciências Humanas, Sociais e Agrárias, Universidade Federal da Paraíba \\ ${ }^{3}$ Docente do Departamento de Ciências Fundamentais e Sociais, Centro de Ciências Agrárias, Universidade Federal da Paraíba \\ * Autor para correspondência: dayanecristinelacerda@gmail.com
}

Recebido em 28 de outubro de 2016. Aceito em 13 de fevereiro de 2017. Publicado em 29 de julho de 2017.

\begin{abstract}
Resumo - A meliponicultura é uma atividade alternativa para agricultores que podem se beneficiar dos seus produtos para a comercialização. Objetivou-se identificar a preferência da orientação na nidificação da Scaptotrigona postica em colmeias octogonais. Foram estudadas 16 colônias de abelhas nativas da espécie S. postica em colmeias octogonais, modelo ISA 2014. As colmeias foram testadas com as colônias durante três dias seguidos, com observações realizadas a cada 3 horas. Cada colmeia octogonal foi colocada em suporte de madeira à 1,30 m de altura com oito orifícios de escolha para nidificação, sendo estes para os pontos cardeais (N, S, L, O) e para os colaterais (NE, SE, SO, NO). Observou-se que 85\% das abelhas de S. postica na Zona da Mata Pernambucana (MPZ) têm preferência de nidificação para Oeste e Noroeste (NO), com maior prevalência de NO (89\%) e menor para SE (18\%). Conclui-se que as abelhas de $S$. postica da ZMP têm preferência de nidificação para a parte ocidental da colmeia, especialmente para as direções NO e O.
\end{abstract}

Palavras-chave: Orientação magnética; Meliponíneos; EnXameação.

INFLUENCE OF CARDINAL AND COLLATERAL POINTS ON THE NESTING OF NATIVE BEES IN OCTAGONAL BEE HIVES

ABstract - Meliponiculture is an alternative activity for farmers who can benefit from its products for marketing. The aim of this study was to identify the direction preference in the nesting of Scaptotrigona postica in octagonal hives. Sixteen colonies of native bees (S. postica) in octagonal hives, model ISA 2014, were studied. The hives were tested with the colonies during three consecutive days, with observations made every 3 hours. Each octagonal hive was placed on a wooden support at $1.30 \mathrm{~m}$ height with eight holes for nesting relating to cardinal (N, S, E, W) and collateral (NE, SE, NW, SW) points. It was observed that $85 \%$ of the $S$. postica bees, in the "Zona da Mata Pernambucana" (ZMP), prefer to nest on the West (W) and Northwest (NO) sides of the hive, with a higher prevalence on the NO (89\%) and a lower one on the SE $(18 \%)$ sides. It is concluded that the $S$. postica bees in the ZMP have a nesting preference for the Western side of the hive, especially for the NO and W points.

KEYwORDS: MAGNETIC ORIENTATION; MELIPONINI; SWARMING.

INFLUENCIA DE LOS PUNTOS CARDiNALES Y COLATERALES EN LA NIDIFICACIÓN DE LAS ABEJAS NATIVAS EN COLMENAS OCTOGONALES

RESumen - La meliponicultura es una actividad alternativa a los agricultores que pueden beneficiarse de sus productos para la comercialización. El objetivo de este estudio fue identificar la preferencia de orientación en el anidamiento de abejas (Scaptotrigona postica) en colmenas octogonales. Se investigaron 16 colonias de abejas nativas de la especie $S$. postica en 
colmenas octogonales, modelo ISA 2014. Las colmenas se ensayaron con las colonias durante tres días consecutivos, con observaciones cada 3 horas. Cada colmena octogonal se puso sobre un soporte de madera a 1,30 m de altura con ocho agujeros para el anidamiento de las abejas referentes a los puntos cardinales (N, S, E, O) y colaterales (NE, SE, SO, NO). Se observó que el $85 \%$ de las abejas de la especie $S$. postica de la Zona da Mata Pernambucana (ZMP) prefieren anidarse al Oeste (O) y al Noroeste (NO) con mayor prevalencia al NO (el 89\%) e inferior al SE (el 18\%). Se concluye que las abejas S. postica de la ZMP prefieren anidarse en la parte occidental de la colmena, especialmente al NO y O.

Palabras clave: Orientación magnética; Meliponíneos; Enjambrazón.

\section{INTRODUÇÃO}

A criação de abelhas sem ferrão está adquirindo adeptos, decorrente de vários motivos, entre os quais a geração de renda e facilidade de manejo que a criação dessas espécies proporciona. Para o produtor rural, os meliponíneos são relevantes, uma vez que constituem-se em alternativa de produção sustentável. Além dos produtos e subprodutos advindos dessa prática, a polinização é o maior benefício que estes animais proporcionam para uma sustentabilidade ambiental. A meliponicultura ainda favorece a adoção da prática de sistemas agroflorestais diversos, os quais servem como fonte de alimento para os meliponíneos e de, forma indireta, contribui para a soberania alimentar das famílias camponesas (Oliveira et al. 2013).

A criação dos meliponíneos é conhecida desde os povos indígenas os quais foram os primeiros a domesticarem estes insetos sociais (Kerr et al. 1996). A criação de abelhas nativas foi regulamentada pelo Conselho Nacional do Meio Ambiente (CONAMA) na Resolução no 346/2004, que disciplina a utilização das abelhas silvestres nativas, bem como a implantação de meliponários (CONAMA 2004). Esta Resolução, por sua vez, reconhece o valor da meliponicultura para a economia e sua importância na polinização, estabilidade dos ecossistemas e na sustentabilidade da agricultura. Neste contexto, a meliponicultura apresenta-se como uma atividade que pode ampliar a produção diversificada de produtos agrícolas, agroflorestais e vegetação natural (Venturieri 2008).

A polinização realizada pelas abelhas ocorre de forma natural e involuntária. Essas, ao se locomoverem entre uma flor e outra, buscando coletar pólen e néctar para o suprimento alimentar da sua colmeia, levam, também, o pólen encaixado em suas corbículas (Nogueira-Neto 1997, p. 241). A função da polinização dos meliponíneos é algo soberano. Seu benefício ao ecossistema transpõe qualquer vantagem gerada pelos diversos produtos advindos da meliponicultura, como mel, pólen, geleia real e própolis (Michener 2007; Coletto-Silva 2005). Estes mesmos autores afirmam que para assegurar a continuação dessa ação é preciso preservar as abelhas, entendendo que, sem a polinização, todos os ecossistemas seriam severamente afetados, assim como a produção agrícola.

Para cada espécie de meliponíneo há diferenças de comportamento (fisiologia, morfologia, biologia e adaptação ao ambiente). Tais características auxiliam o meliponicultor a posicionar sua colmeia em ambiente com condições à sua sobrevivência e desenvolvimento (Witter 2014, p. 77).

A abelha em estudo, Scaptotrigona postica, é uma espécie que possui características próprias de organização social, exercendo - na colmeia - funções bem definidas; são as fêmeas que executam as tarefas da colônia; a rainha, com a responsabilidade de reprodução; e as operárias, com as demais tarefas, dentro e fora da colmeia. Já os machos, possuem maior relevância no período reprodutivo (Maschio et al. 2013). A fisiologia das operárias permite que estas ponham ovos não fecundados. Porém, em $S$. postica, esses servem, também, para alimentar a 
rainha (Santos e Cruz-Landim 2002). Estes autores indicam que a diferença na reprodução de rainha e operária, nesta espécie, consiste na quantidade de alimento disponibilizado nas células de cria, onde essas são maiores em diâmetro para a rainha, e menores para as operárias. Com isto não há diferenciação entre essas castas até chegar na fase de pré-pupa, onde as diferenças são observadas.

A mandíbula de $S$. postica é algo importante a ser estudado, uma vez que é um órgão responsável por um dos principais mecanismos de defesa da espécie. Estas abelhas possuem glândulas mandibulares características e dois tipos de glândulas intramadibulares, as unicelulares e epiteliais (Maschio et al. 2013).

Esta abelha tem a capacidade de percorrer longas distâncias em seus voos diários. As abelhas desta espécie são forrageiras eficientes, pois mesmo com seu porte pequeno, conseguem percorrer uma distância significativa de até $750 \mathrm{~m}$ e, em seguida, retornar a colmeia (Nogueira 1997).

Segundo Souza et al. (2015), S. aff. postica possui a preferência pelo forrageamento da espécie arbórea Borreria verticillata da família Rubiaceae. Estes autores indicam que essa espécie de abelha nativa é um eficiente agente de polinização, uma vez que foram identificados diversos tipos de pólen na própolis dessa espécie do município de Barra do Corda-MA.

A arquitetura do orifício de entrada da colônia de $S$. postica é constituída por cerume (Nogueira-Neto 1997, p. 5). Os meliponíneos distinguem-se, entre as muitas características, por seu tamanho, cor, organização social, propriedades do mel, estrutura interna da colônia e, também, pelo orifício de entrada do ninho. O peso de seu corpo é em torno de 0,00926 g e, essas abelhas, geralmente nidificam em troncos de árvores, com preferência pelas espécies arbóreas Imburana (Commiphora leptophloeos), Catingueira (Poincianella pyramidalis), Faveleira (Cnidoscolus phyllacanthus) e Umbuzeiro (Spondias tuberosa) (Aquino 2006, p. 41).

Essa espécie de meliponíneo pode ser encontrada em diversas regiões, o que demonstra uma boa adaptabilidade a ecossistemas variados. Predominantemente, a Scaptotrigona sp. pode ser encontrada em algumas microrregiões da Paraíba, destacando-se o brejo, curimataú e seridó (Aquino 2006, p. 41).

Os meliponíneos possuem preferências ambientais que promovem seu bem-estar, garantindo a sua sobrevivência e permanência em um determinado local. Quando esses insetos possuem pasto apícola disponível em região de origem, isso se torna em algo positivo à sua permanência; quando expostas, porém, a outro babitat, cujas flores não estão adaptadas, ocorre o comprometimento de seu desenvolvimento e sobrevivência (Villas-Boas 2012; Venturieri 2008). Segundo Almeida (2008) as abelhas são animais sensíveis a diversos fatores climáticos, que dificultam ou favorecem as atividades internas e externas a colmeia, sendo necessário que o produtor promova condições favoráveis que possibilitem o seu bem-estar.

Os meliponíneos possuem vários mecanismos de comunicação, definindo seu comportamento dentro e fora da colmeia. No forrageamento, por exemplo, elas marcam sua colmeia ou gravam o percurso de diversas maneiras e transmitem essa informação as demais campeiras (Kerr et al. 1996; Nogueira-Neto 1997). Estes mesmos autores afirmam que a $S$. postica demarca seu trajeto pelo uso de cheiro, o que permite a ida e o retorno das campeiras a sua colmeia.

Com relação ao comportamento e orientação dos animais, sabe-se que estes são sensíveis a diversos estímulos, afinal vivem em um ambiente complexo, tendo as espécies adaptabilidade a região onde estão inseridas (Oliveira et al. 2013). As abelhas podem ser influenciadas por diversos fatores, determinados pelo ambiente interno e, principalmente, o externo à colmeia, que promovem, além do comportamento de organização, a sua orientação de voo e escolha do local de nidificação (Lucano 2006, p. 26). 
Outras influências que interferem no comportamento dos meliponíneos são apontados por muitos autores em diversas áreas de estudo. A magnetorecepção, conhecida como a capacidade sensorial de traduzir os sinais (magnéticos) percebidos pelo campo magnético da terra, por exemplo, influencia no comportamento e desenvolvimento das atividades dos seres vivos (Wajnberg et al. 2010). Pode-se dizer que as abelhas são espécies que possuem alta sensibilidade às variações de intensidade que ocorrem no campo magnético da terra (Schiff 1991). A magnetorecepão é, por sua vez, um campo de estudo eficaz para entender o comportamento e as influências que determinam as ações dos meliponíneos, bem como de outros animais que são sensíveis, também, ao campo magnético da terra (Lucano 2006).

Vários estudos têm sido realizados em animais de várias espécies na tentativa de comprovar o local no qual se situa o órgão magnetosensor. Nas abelhas, aponta-se nos pelos escuros do abdômen dorsal (Keimet et al. 2000). Nesses insetos, os órgãos sensores mais complexos são as antenas e os olhos (Lucano 2006). Wajnberget et al. (2010) sugerem, também, que o abdômen das abelhas de A. mellifera, por exemplo, servem como o órgão magnetosensor, enquanto que em formiga e abelhas $S$. quadripunctata têm apontado para a antena, que é um sensor tátil, olfatório e de gravidade, como um órgão sensor magnético.

Segundo Keim et al. (2000), foram encontrados cristais de magnetita nos corpos de alguns seres vivos, considerando que estes seriam os responsáveis pela magnetorecepção entre os animais e o campo magnético da terra. Estes mesmos autores, identificaram no estudo realizado em rainha das abelhas $A$. melifera e $S$. postica que os grânulos localizam-se em seu corpo gorduroso.

Esforços têm sido realizados a fim encontrar uma resposta sobre a influência do campo magnético no comportamento animal (Kirschvink et al. 2010). Em especial, o comportamento e orientação de muitos animais são aparentemente afetados pela direção e intensidade do campo magnético da Terra (Kirschvink e Gould 1980). As abelhas são um dos melhores e mais estudados animais sobre a magnetorecepção; possivelmente por serem animais eusociais, ou seja, vivem em comunidade, além de possuirem um sistema de magnetorecepção para posicionamento e orientação de seus ninhos (Chin-Yuan et al. 2007; Kirschvink et al. 1997).

Em estudo realizado por Esquivel et al. (2007), detectou-se que efeitos do campo geomagnético nas direções de voo do ninho de Schwarziana quadripunctata (Meliponini) foram significativos num dia de tempestade magnética, no qual as nanopartículas magnéticas nestas abelhas poderiam estar envolvidas no efeito observado da tempestade geomagnética. Além da magnetorecepção, vários outros fatores corroboram para os estímulos ao comportamento de um ser vivo, como acronobiologia, apontada como ciência baseada nos ritmos biológicos dos organismos do próprio sujeito, definindo sua fisiologia e comportamento (Araújo e Marques 2002).

O comportamento do ser vivo influenciado por uma ritmicidade, também denominada como ritmo circadiano (relógio biológico), é vulnerável às mudanças do ambiente como a temperatura e período do dia (luz solar) do campo geomagnético da terra e por sua ritmicidade, definindo a frequência e os tipos de atividades diárias adotadas (García 2004). Segundo Moro et al. (2012), o estudo da influência dos ritmos circadianos nas variáveis cardiovasculares, psicomotoras e neuromusculares em seres humanos, por exemplo, não sofrem influência na hora do dia (10, 16 e 20 h).

Os meliponíneos são animais que se utilizam de vários mecanismos que os permitem reconhecer o ambiente, o que auxiliam esses insetos para que não se percam nos voos laborais. Esses animais possuem uma memória tida como temporal, na qual o ambiente é percebido e internalizado por todas as abelhas que desempenham a mesma função na colmeia, atuando de forma padronizada (Gonçalves e Marques 2012). 
Todos os seres vivos utilizam mecanismos de orientação no meio que os circunda na tentativa de preservar suas espécies (Aragão 1985). Em espécies de abelhas, é sabido que o comportamento de orientação é influenciado pelo campo geomagnético da Terra (Lucano 2006), que por sua vez traduz-se como um fenômeno extremamente dinâmico descrito por um vetor local, com variações diárias e seculares de magnitude e direção (Esquivel et al. 2007).

Sabe-se que as abelhas geralmente são condicionadas a se adaptarem conforme a escolha da infraestrutura do meliponário e/ou condicionamento das colmeias; porém, é sabido que esses insetos eusociais são altamente sensíveis às condições internas e externas a colmeia, e muitas vezes à enxameação da colônia, ou mesmo sua morte. Nesta perspectiva, o propósito desta pesquisa foi avaliar as seguintes premissas de preferência de Scaptorigona postica: 1. Altura de nidificação; e, 2. Orientação magnética de nidificação. A resposta a esses questionamentos podem consolidar ou mudar paradigmas de manejo na criação dessas abelhas.

Desta forma, torna-se imperativo elucidar a seguinte arguição-problema: Qual a preferência na orientação de nidificação da $S$. postica?

Considerando essas interfaces de mecanismos que influenciam o comportamento de orientação de meliponíneos, objetivou-se com este trabalho identificar a preferência da orientação de nidificação da Scaptotrigona postica em colmeias octogonais.

\section{Material e MÉtodos}

O experimento foi realizado no período de 29 de julho a 21 de agosto de 2016, na Propriedade São Saruê, município de Igarassu (Latitude $7^{\circ} 50^{\prime} 3^{\prime \prime} \mathrm{S}$ e Longitude $34^{\circ} 54^{\prime} 23^{\prime \prime} \mathrm{W}$ ), região metropolitana de Recife-PE, localizado na Zona da Mata do estado. A propriedade possui 3 ha, com incidência de diversas espécies arbóreas nativas, com predominância das espécies Algernonia kublmannii (Emmerich) G.L.Webster, Goupia glabra Aubl., Eugenia egensis DC., Astronium lecointei Ducke e frutíferas Anacardium occidentale L. e Annona muricata L.

A propriedade é cortada pelo Rio Tabatinga, principal fonte de água para as abelhas, localizado a aproximadamente a $150 \mathrm{~m}$ de distância do local do experimento. Sua nascente fica dentro da propriedade Usina São José, e possui uma faixa de $14 \mathrm{~km}$ de extensão e desagua num braço de mar no município de Itapissuma-PE.

Foram estudadas 16 colônias de abelhas nativas da espécie Scaptotrigona postica para se avaliar a preferência da orientação de nidificação. Colônias da espécie foram distribuídas dentro de colmeias octogonais, cada uma contendo uma população da abelha nativa.

As colmeias octogonais, modelo ISA 2014, foram confeccionadas em material de MDF (Medium-Density Fiberboard) com $6 \mathrm{~mm}$ de espessura e com tampa. Em cada face lateral da colmeia octogonal $(11 \mathrm{~cm}$ de diâmetro) foram perfurados um orifício com $9 \mathrm{~mm}$ de diâmetro, a $9,8 \mathrm{~cm}$ de altura a partir da parte de baixo da colmeia, os quais corresponderam às direções de orientações magnéticas, pontos cardeais Norte (N), Sul (S), Leste (E), Oeste (O) e colaterais Noroeste (NO), Nordeste (NE), Sudoeste (SO), Sudeste (SE). Os orifícios foram posicionados com orientação de uma bússola do aplicativo Compass em smartphone Moto G ${ }^{\circledR}$ (2 $2^{a}$ Geração).

As colmeias selecionadas para o experimento foram colocadas na colmeia de origem, no local do experimento dois dias antes da introdução nas colmeias octogonais, a fim de que as abelhas pudessem conhecer o local, fonte de água e alimentação. No terceiro dia as colônias (discos de cria) foram retiradas da colmeia de origem e transferidas para as colmeias octogonais as $08: 00 \mathrm{~h}$, dando-se início a coleta de dados. O manuseio foi realizado 
com cautela para não romper os potes de pólen, pois estes atraem pragas como os forídeos (Pseudohypocera kertes:i).

As colmeias foram experimentadas com as colônias durante três dias na $1^{\mathrm{a}}$, $3^{\mathrm{a}}$ e $4^{\mathrm{a}}$ semana, e na $2^{\mathrm{a}}$ semana durante 4 dias; o tempo de análise decorreu da evolução natural da escolha do orifício de nidificação realizada pelas colônias.

A coleta de dados foi realizada através da observação de abertura e fechamento dos orifícios da colmeia octogonal, a cada 3 horas, nos períodos de 08:00h, 11:00h, 14:00h e 17:00h, de cada dia, fazendo-se anotações referentes a evolução do fechamento do orifício de nidificação. No primeiro dia de experimento de cada semana de estudo, às 08:00 h da manhã (o primeiro horário de coleta de dados) as colmeias de origem da colônia foram abertas e a família de abelha nativa introduzida na colmeia octogonal. Nos períodos de análises do mesmo dia, e nos dias consecutivos, foram realizadas apenas observações e anotações dos dados.

Concomitantemente, foram coletados dados climáticos da mini-estação meteorológica Davis Instruments ${ }^{\circledR}$, Vantage PRO2, equipamento cedido pelo Laboratório de Fitotecnia (LF) da Universidade Federal da Paraíba (UFPB), durante o período de realização do experimento. Com esse equipamento foram coletados os dados referentes as características climáticas do ambiente em que o estudo foi desenvolvido como a temperatura, umidade, velocidade e direção do vento. A mini-estação meteorológica foi instalada a uma distância de 9 metros das caixas octogonais, e totalmente ao sol, para correta verificação das condições climáticas.

Devido a pouca florada na época do ano em que o experimento foi realizado, utilizou-se alimentação artificial para todas as colmeias estudadas. Utilizou-se o método utilizado por Chagas e Carvalho (2005) para a alimentação artificial, o qual consiste em um bebedouro de sabiá, contendo um xarope, composto por $250 \mathrm{~g}$ de mel de Apis mellifera, 1 litro de água, 1,5 Kg de açúcar cristal e meio limão, e um graveto de madeira pequeno, para evitar o afogamento das abelhas indígenas. Como suporte para a instalação dessas colmeias, foram utilizadas cinco estacas de madeira (tipo prateleira), medindo $1,50 \mathrm{~cm}$, fixados no solo com profundidade de $0,20 \mathrm{~cm}$, colocadas em linha reta a uma distância de $5 \mathrm{~m}$ de uma para a outra. As estacas ficaram permanentemente no local durante as quatro semanas de estudo. Também foram utilizadas telhas de fibrocimento (Brasilit ${ }^{\circledR}$ ), sob as colmeias octogonais, para proteção contra a chuva e contribuição para o sombreamento.

Para a proteção contra as pragas, optou-se pelo manejo utilizado por Venturieri (2008). Desse modo, foram inseridos, em cada colmeia octogonal, três recipientes com tampa e pequenos furos, tipo saleiro, com uma pequena lâmina de vinagre comum que serviu como armadilha para P. kertesq̨i. P. kertesそ̨i. Essas pequenas moscas que se alojam na colmeia, e rapidamente depositam suas larvas, podem danificar toda a sua estrutura interna da colônia, e com sua rápida proliferação, pode promover a morte da colmeia (Venturieri, 2008, p. 51).

Considerando que as formigas atacam colmeias fracas, provavelmente submetidas a recente divisão (Venturieri 2008, p. 52), utilizou-se óleo queimado na base das estacas que deram suporte as colmeias neste experimento.

Os dados coletados foram organizados em planilha no Microsoft Excel ${ }^{\circledR} 2013$ e submetidos à estatística por meio do software SAS ${ }^{\circledR} /$ STAT 9.3 (SAS, 2012). Os níveis de cada fator, orientação, hora e dia e probabilidade de se encontrar orifício aberto foram testados, comparados isoladamente pelo teste de Tukey ( $\mathrm{x} \leq 0,05)$. Os efeitos dos fatores ambientais quantitativos (temperatura média, umidade relativa do ar, direção e velocidade média do vento) sobre a probabilidade de se encontrar o orifício aberto foram ajustados por meio de regressão logística. 


\section{REsultados E Discussão}

Foram realizadas 2.080 observações durante 13 dias de coleta de dados de nidificação nas colmeias octogonais. Observou-se que 85\% das abelhas Scaptotrigona postica, da Zona da Mata pernambucana, têm preferência de nidificação para o Oeste $(\mathrm{O})$, Noroeste $(\mathrm{NO})$ e Norte $(\mathrm{N})$. Entretanto, essa abelha possui uma preferência nula ou baixa (0-5\%) para os pontos cardeais Sul (S) e Leste (E) e colateral Sudeste (SE).

Ao se detectar que a abelha $S$. postica têm preferência de nidificação em relação a orientação magnética, torna-se imprescindível se avaliar a orientação das colmeias em criação racional de $S$. postica. Almeida (2008) explica que além do comportamento de enxameamento de forma sazonal, podem ocorre interferências externas a colmeia como a temperatura, escassez de água e invasão de predadores, exercendo um estímulo imediato. As práticas de manejo de uma colmeia cujo controle e correção desses fatores são considerados, considerando, também sua orientação magnética, possibilita uma criação de meliponíneos adequada, favorecendo a sua ambiência e propiciando seu melhor desenvolvimento e produtividade.

Na primeira semana de avaliação observou-se que a maioria dos orifícios abertos encontra-se nas posições Sudoeste (SO), Oeste (O), Noroeste (NO) e Norte $(\mathrm{N})$; por outro lado, na segunda semana permaneceu, predominantemente, abertos os orifícios situados na posição Oeste $(\mathrm{O})$ e Noroeste (NO). Este comportamento permaneceu nas demais semanas de avaliação (terceira e quarta). Na terceira semana não se observou diferença entre as posições Oeste $(\mathrm{O})$, Noroeste $(\mathrm{NO})$ e Norte $(\mathrm{N})$. Também pode-se observar nestas avaliações que as abelhas $S$. postica iniciam o fechamento dos orifícios das colmeias localizadas entre a região Nordeste (NE) e Sul (S) e, que em três a quatro dias já se tem boa definição da preferência das abelhas pela localização de entrada na colmeia.

De acordo com os dados observados, notou-se que na primeira semana de observação, onde houve maior incidência em relação a direção da abertura do orifício, a coordenada Oeste $(\mathrm{O})$ apresentou $98 \%$ de chances para a abertura do mesmo, enquanto que a menor estimativa foi observada na direção Sudeste (SE) com 70\%. Estes dados foram observados na primeira semana de coleta.

Observou-se que houve maior incidência de encontrar orifício aberto na direção Oeste $(\mathrm{O})$, com $68 \%$ da estimativa observada; já a menor estimativa foi para o Sudeste (SE) com $25 \%$, de modo que estes dados foram observados na segunda semana de pesquisa de campo. A maior probabilidade de orifícios com nidificação abertos ocorreu na direção Noroeste (NO), com uma estimativa de 77\% na terceira semana de observação. Por outro lado a menor estimativa ficou com 19\% na direção Sul (S).

$\mathrm{Na}$ quarta semana de observação a direção onde houve maior incidência de abertura dos orifícios foi a Noroeste (NO) com 89\% da estimativa observada, já a que apresentou menor estimativa foi a direção Sudeste (SE) com 18\% (Figura 1).

Em contraste, Silva (2016) observou, em estudo realizado nos municípios de Lagoa Seca e Areia-PB, que a maior probabilidade de encontrar orifícios abertos da espécie Melipona scutellaris em colmeias octogonais foi com orientação para NE (85\%), L (78\%), N (73\%).

Segundo Vaz (2015) as abelhas Frieseomellita díspar tiveram maior frequência de nidificação para os pontos Leste (L), Nordeste (NE), Norte $(\mathrm{N})$ e Oeste $(\mathrm{O})$, condicionadas em colmeias octogonais, em Jardim do SeridóRN. 
Figura 1 - Probabilidade de encontrar orifícios abertos em colméias octogonais modelo 2014 contendo abelhas Scaptotrigona postica em relação à orientação do orifício no município de Igarassu-PE. Médias seguidas pela mesma letra não diferem entre si pelo teste de Tukey $(\mathrm{p} \leq 0,05)$.

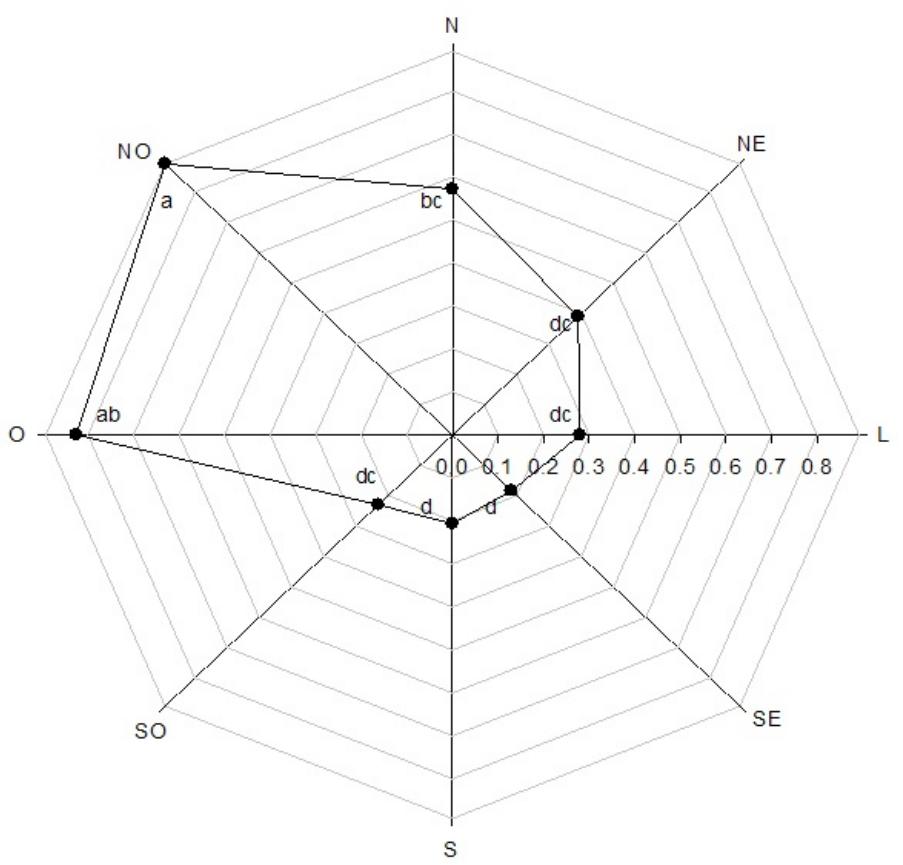

Ferreira (2009) observou, em estudo realizado na Zona da Mata paraibana, que a orientação de nidificação de espécies de abelhas e vespas foi o direcionado ao Leste $(\mathrm{L})$. O autor relaciona esta escolha devido à direção do vento local que possui incidência predominante para o Sudeste (SE) e Leste (L).

Na primeira semana de observação, a partir das 8:00 horas, a probabilidade de encontrar orifícios abertos nas colmeias octogonais é muito alta (97\%). Porém, essa probabilidade diminuiu nos horários subsequentes (95 a 84\%), chegando ao fim do dia com 54\%. No primeiro dia de observação, a probabilidade de encontrar orifícios abertos nas colmeias octogonais é muito alta (100\%). Porém, essa probabilidade diminuiu nos dois dias subsequentes (81 e 16\%).

$\mathrm{Na}$ segunda semana de estudo observou-se, a partir das 8:00 horas, que a probabilidade de encontrar orifícios abertos nas colmeias octogonais é de $46 \%$. Porém, essa probabilidade oscila, diminuindo a $42 \%$ e um pequeno aumento de 43\%, ao final do dia; as 17:00 horas essa probabilidade diminui significativamente, alcançando $24 \%$ na segunda semana de estudo. No primeiro dia, a probabilidade de encontrar orifícios abertos nas colmeias octogonais é de $84 \%$. Porém, essa probabilidade diminuiu nos dois dias subsequentes (43, 24 e $10 \%)$.

$\mathrm{Na}$ terceira semana de estudo, observou-se que a partir das 8:00 horas da manhã a probabilidade de encontrar orifícios abertos nas colmeias octogonais é de 55\%. Porém, essa probabilidade aumenta (56\%) com a elevação da temperatura as 11:00 horas, e diminui (50\%) após as 14:00 horas quando percebe-se uma temperatura mais amena, a probabilidade apresenta declínio no final do dia as 17:00 horas com $22 \%$. No primeiro dia, a probabilidade de encontrar orifícios abertos nas colmeias octogonais é 76\%. Porém, essa probabilidade diminuiu nos dois dias subsequentes (41 e $20 \%$, respectivamente).

$\mathrm{Na}$ quarta semana de estudo, a partir das 8:00 horas da manhã, a probabilidade de encontrar orifícios abertos nas colmeias octogonais é de $62 \%$; as 11:00 horas, atinge uma probabilidade alta de $58 \%$, diminuindo com o passar do dia; as 14:00 horas, atinge 47\%, e as 17:00 horas, 19\%. No primeiro dia, a probabilidade de encontrar orifícios abertos nas colmeias octogonais é 87\%. Porém, essa probabilidade diminuiu nos dois dias 
subsequentes (50 e 47\%) [Figura 2].

Figura 2 - Probabilidade de encontrar, na $4^{a}$ semana, orifícios abertos em colmeias octogonais modelo ISA 2014 contendo abelhas da espécie Scaptotrigona postica em relação A) aos horários e B) em relação aos dias após a instalação em IgarassuPE. Em cada gráfico, médias seguidas pela mesma letra não diferem entre si pelo teste de Tukey $(\mathrm{p} \leq 0,05)$.
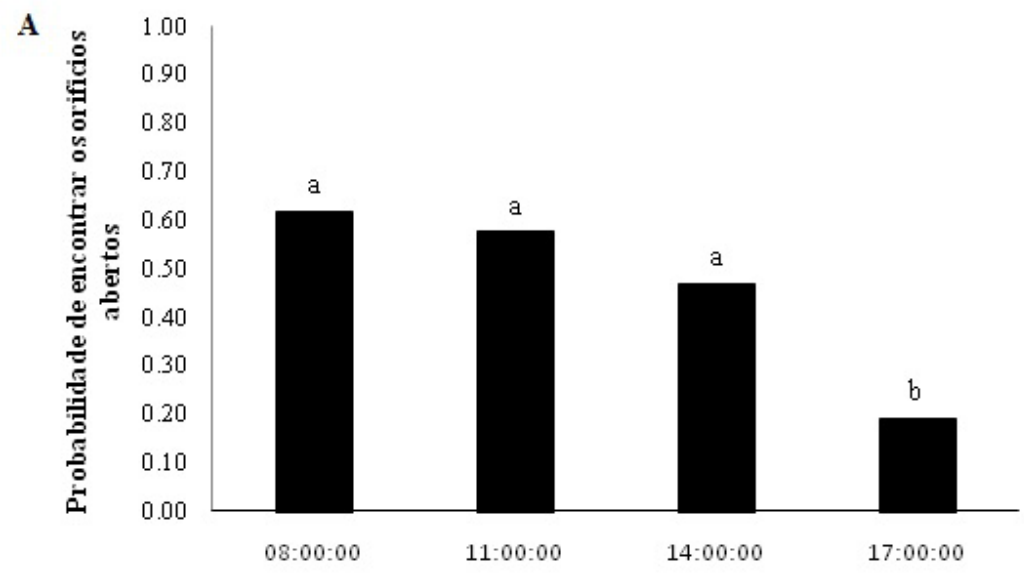

B

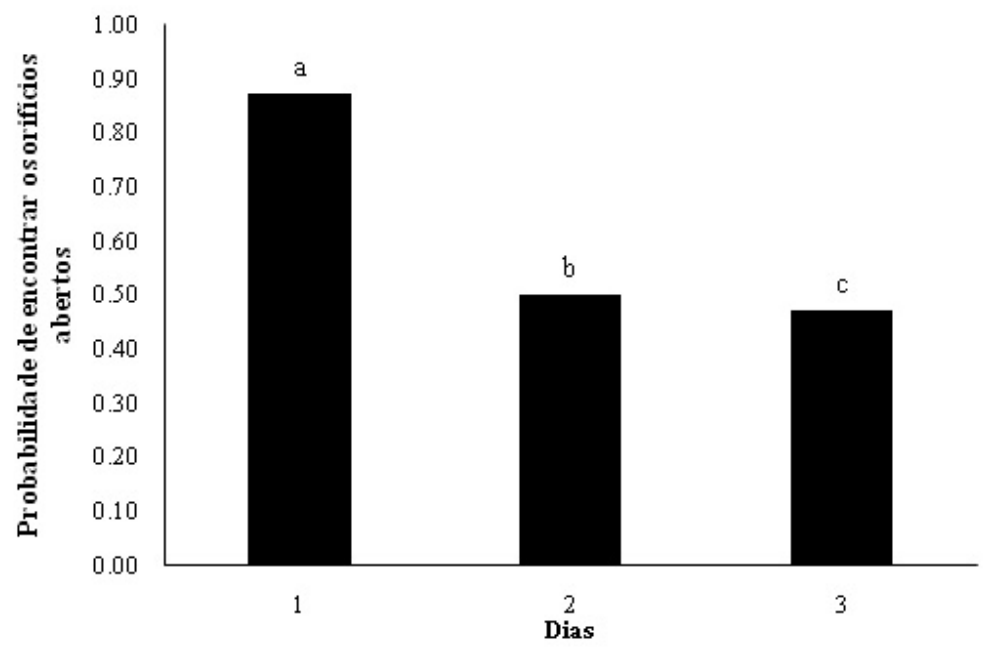

Nas quatro semanas de estudo, a probabilidade de encontrar os orifícios abertos nos primeiros horários de coleta de dados é alta; algumas vezes mantendo-se estável, até as 14:00 horas, diminuindo até chegar ao final da tarde (17:00 horas), com uma probabilidade muito baixa, demonstrando que suas atividades se acentuam nos períodos mais quentes do dia. Da mesma forma ocorre na probabilidade de encontrar os orifícios das colmeias abertos nos dias do experimento, seguindo-se de um percentual acentuado no primeiro dia do ensaio, chegando ao último dia (terceiro ou quarto) com uma probabilidade muito baixa, o que demonstra que ao final de cada semana de estudo, pode-se constatar exatamente qual o orifício de preferência dessas abelhas.

Quanto à probabilidade de abertura dos orifícios das colmeias octogonais com relação aos horários, segundo Silva (2016), pela manhã a probabilidade é alta, atingindo $71 \%$ de chances, reduzindo-se a $68 \%$ e a $60 \%$ nos horários seguintes de observação para o experimento realizado com a espécie Melipona scutellaris.

Quanto a probabilidade de encontrar os orifícios abertos com relação aos dias, ainda segundo Silva (2016) no primeiro dia é de $99 \%$, chegando ao último dia a $23 \%$ de chance. Quanto ao início de atividades das abelhas, seja de abertura de orifícios da entrada da colmeia ou de voo, o horário é um fator determinante, pois marca no tempo as condições ambientes ideais para o funcionamento biológico dos meliponíneos. Com relação a esse aspecto, segundo Oliveira et al. (2012) no estudo realizado em Mossoró, RN, em períodos distintos (seco e úmido), observou-se que as atividades externas, nas colmeias da espécie Melipona subnitida Ducke, tiveram início 
as 5:00 horas da manhã, com a umidade a $90 \%$ e temperatura de $20^{\circ} \mathrm{C}$.

Para os dados da temperatura, umidade relativa do ar e velocidade do vento, pôde-se constatar que os fatores meteorológicos durante a condução do ensaio não foram ajustados satisfatoriamente ao modelo para explicar suas influências sobre as dinâmicas de fechamento dos orifícios. Os fatores abióticos do ambiente foram insignificantes estatisticamente, não influenciando na probabilidade de encontrar orifícios abertos em colmeias octogonais, modelo ISA 2014, contendo abelhas S. postica.

A orientação do vento é um fator determinante no voo das abelhas. A escolha da direção do orifício de entrada das colmeias pode estar condicionado a direção do vento (contra ou a favor), geralmente adotando um comportamento natural de escolha ao sentido oposto do vento para nidificar (Hilário 2007). Neste estudo, os dados da direção do vento foram apresentaram efeito estatístico. No que diz respeito a probabilidade de se encontrar os orifícios abertos com relação a direção do vento, na primeira semana de avaliação, observou-se que a maioria dos orifícios abertos encontram-se nas posições Leste (L) e Sudeste (SE) [Figura 3]; enquanto que na segunda semana, permaneceu, predominantemente, abertos os orifícios situados na posição Oeste $(\mathrm{O})$ e Noroeste (NO). Na terceira semana de avaliação prevaleceu os pontos Leste (L) e Sudoeste (SO) e na quarta semana foi maior nos pontos Nordeste (NE) e Sudeste (SE). Apenas na terceira e quarta semana, observou-se efeito das direções do vento sob a probabilidade de encontrar os orifícios das colmeias abertos.

Na primeira semana de estudo, observou-se que a probabilidade de encontrar orifícios abertos em relação a direção do vento foi maior nos pontos Leste (L) e Sudeste (SE), com 100\% (Figura 3). A probabilidade diminui, atingindo $62 \%$, nas direções nordeste $(\mathrm{NE})$ e norte $(\mathrm{N})$, e $42 \%$ no sudoeste $(\mathrm{SO})$; a menor probabilidade é de $28 \%$ para o Noroeste (NO). Como não houve diferença estatística, não observou-se efeitos dos ventos sobre os orifícios. Para os pontos Sul $(\mathrm{S})$ e Oeste $(\mathrm{O})$ não se pode estimar uma probabilidade de influência do vento, pois não se detectou ventos nessas direções.

Observou-se na segunda semana de estudo, que a probabilidade de encontrar orifícios abertos de acordo com a influência do vento, foi maior no ponto Oeste $(\mathrm{O})$ com 100\%. Com probabilidade elevada também para o ponto colateral Noroeste (NO) com 87\%, com 47\% para o Nordeste (NE), 30\% Leste (L) e 28\% Sudeste (SE). Como não houve diferença estatisticamente significativa, não ocorreram efeitos dos ventos sobre os orifícios. Para os pontos Norte $(\mathrm{N})$, Sudoeste $(\mathrm{SO})$ e Sul $(\mathrm{S})$ não se pode estimar uma probabilidade de influência do vento, pois não se detectou sua incidência nessas direções.

Observou-se, na terceira semana de estudo, que a probabilidade de encontrar orifícios abertos de acordo com a influência do vento, foi maior no ponto Leste $(\mathrm{L})$ com $58 \%$. Também foi constatada probabilidade elevada para o ponto colateral Sudoeste (SO), com 49\%, 39\% para o Nordeste (NE) e 29\% Sul (S); desta forma, ocorrendo o efeito do vento para os orifícios. Não foram detectadas incidência de vento nas direções Norte $(\mathrm{N})$, Nordeste (NE), Oeste (O) e Sudeste (SE).

$\mathrm{Na}$ quarta semana de estudo, a maior probabilidade de encontrar orifícios abertos, com a influência do vento, no ponto Nordeste (NE) foi de 52\%. Houve, também, probabilidade elevada para o ponto colateral Sudeste (SE), com 43\%; 40\%, para o Leste (L); e com menor probabilidade (18\%) para o Sudoeste (SO), detectando-se, assim, efeito do vento para os orifícios. Não foram detectadas incidência de vento nas direções Norte $(\mathrm{N})$, Noroeste $(\mathrm{NO})$, Oeste $(\mathrm{O})$ e Sul (S).

Corroborando com os dados da última semana de análise, Silva (2016), no estudo realizado com a espécie M. scutellaris em colmeias octogonais, modelo ISA 2014, observou que a probabilidade de encontrar orifícios 
abertos de acordo com a influência do vento foi maior para o ponto colateral Nordeste (NE) e a menor probabilidade para os pontos Sul (S), Sudoeste (SO) e Noroeste (NO).

No estudo de Vaz (2015), com a espécie de abelha F. díspar, em colmeias octogonais, ocorreu maior incidência de vento para a direção Leste $(\mathrm{L})$, com uma velocidade média de $0,6 \mathrm{~m} / \mathrm{s}$, e esse ponto cardeal obteve, no segundo dia de observação, maior frequência de abertura (63,89\%). Já colônias de $S$. postica, neste estudo, apresentaram aversão a esses orifícios, optando majoritariamente pelos orifícios opostos. Esse aspecto induz a teoria de que o vento é um fator determinante na escolha do orifício de entrada na nidificação de colônias, onde sua incidência não é positiva na nidificação das abelhas.

O mesmo foi observado no estudo de Hilário et al. (2007), realizado com a espécie Plebeia remota, a qual demonstrou maior atividade de voo quando as direções de vento eram entre $330^{\circ}$ e $150^{\circ}$ (verão), $360^{\circ}$ e $150^{\circ}$ (outono e inverno) e $300^{\circ}$ e $90^{\circ}$ (primavera), enquanto que houve diminuição dessas atividades com vento nas direções entre $180^{\circ}$ e $270^{\circ}$ (todas as estações do ano); ou seja, estes meliponíneos orientam seu voo de acordo com a direção do vento.

Figura 3 - Coleta de dados da preferência de nidificação da Scaptotrigona postica em colmeias octogonais modelo ISA 2014: A) Colmeia octogonal; B) Colmeia octogonal com a marcação de orientação na tampa e formação do orifício de entrada; C) Colmeia com a colônia da Scaptotrigona postica; D) Colmeia com a colônia da Scaptotrigona postica, armadilhas de forídeos e bebedouro de sabiá com alimentação artificial.

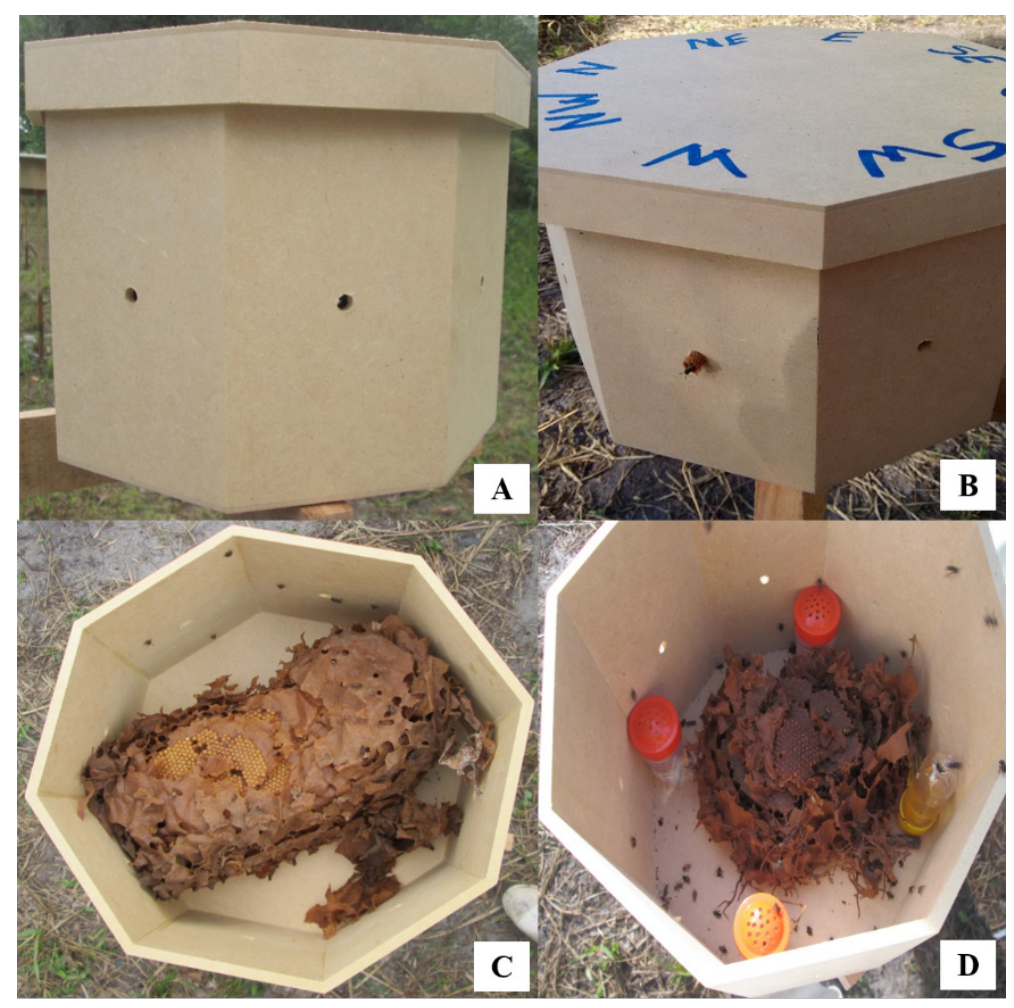

Nos intervalos (das observações) previamente determinados, verificou-se que os meliponíneos desenvolveram normalmente suas atividades de coleta de pólen, néctar e água para a garantia de sua sobrevivência. O mecanismo de defesa demonstrado contra invasores por $S$. postica, observados nesse estudo, foi a presença de três a quatro abelhas guardiãs na parte externa da colmeia, próximas ao orifício de entrada. Observou-se, também, que uma eventual entrada de qualquer outra espécie acionava outras abelhas guardiãs a colocar tais invasores para fora do orifício de entrada. 
Oliveira et al. (2012) verificaram, em estudo realizado no meliponário da Universidade Federal Rural do Semi-Árido (UFERSA), Mossoró, RN, que as atividades externas das abelhas jandaíras (Melipona subnitida Ducke) ocorrem predominantemente pela manhã, com grande quantidade de cargas coletadas, como pólen, néctar, água e barro. Diferentemente, Maranhão por Ramos et al. (2007) observaram, em estudo conduzido em uma área de cerrado no Estado do Maranhão, as abelhas sobrevoavam ao redor do termiteiro, saía e voltava alguns minutos depois, sem nenhum recurso visível.

Nas duas primeiras semanas de estudo, o ataque de $P$. kertesz̧i foi mais acentuado em comparação a $4^{a}$ e última semana de análise. Nesse período de maior intensidade dessa praga, foi observado poucos voos das abelhas para coleta de alimento e água, provocando uma reação de intenso trabalho interno na colmeia, com o fechamento dos orifícios e briga por espaço, numa luta por sobrevivência. Já nas duas últimas semanas de estudo, a presença de $P$. kerteš $i$ foi bastante reduzida e a florada mais numerosa, observando-se a presença de flores próximo ao local do experimento, o que favoreceu o bem-estar das abelhas recém condicionadas as colmeias octogonais. Rech, Schwade e Schwade (2013), em estudo realizado em um meliponário na Amazônia central, encontraram forídeos movimentando-se sobre a colmeia, porém, dificilmente entravam na mesma.

Nas quatro semanas de estudo observou-se que as colmeias possuíam tempos de fechamentos diferentes; em algumas colmeias, as abelhas demoraram mais do que outras para escolherem o orifício de entrada preferido para o ninho. Provavelmente, isso ocorreu devido a fatores como resistência as pragas invasoras, influência dos fatores climáticos e estado da colmeia.

Observou-se uma grande movimentação das abelhas em torno da colmeia no período em torno das 11:30 horas, quando há um aumento de temperatura. Por outro lado, Oliveira et al. (2012) observaram que o ritmo diário de Melipona subnitida, para as atividades externas, começa por volta das 05:00 horas, quando a umidade relativa do ar é alta (90\%), a incidência de radiação é próxima a zero e a temperatura média em torno de $20^{\circ} \mathrm{C}$. E em estudo realizado por Macieira e Proni (2004) as operárias de S. postica apresentaram uma faixa de tolerância térmica entre $-3,5$ e $40^{\circ} \mathrm{C}$ no verão e -4 e $39,5^{\circ} \mathrm{C}$ no inverno, demonstrando uma boa tolerância ao frio.

Em todas as semanas, o comportamento das colmeias foram similares. Na segunda semana de análise, apenas uma colmeia construiu uma estrutura no orifício de entrada e saída escolhido e na $4^{a}$ semana essa ação ocorreu novamente; em duas colmeias, foram construídos um canudo feito de cerume, característico da espécie estudada.

Houve, na quarta semana de estudo, o ataque de abelhas irapuás (Trigona spinipes) nas colmeias do experimento, tentando fazer pilhagem. Neste momento, observou-se que as abelhas lutavam umas com as outras, e se agarravam até caírem do alto das colmeias ao chão. As T. spinipes, quando descobrem o alimentador, progressivamente conseguem expulsar toda a família de abelha do seu ninho (Keer 1996). Porém, as famílias estudadas resistiram ao ataque dos T. spinipes que persistiram no ataque durante dois dias consecutivos. A atração dessas abelhas pilhadoras, assim como outras que possuem essa mesma característica, se deve a alimentação artificial fornecida a colmeias fracas; dessa forma, ao serem alimentadas, tornam-se vulneráveis (Nogueira-Neto 1997). Como alternativa ao ataque de espécies pilhadoras, Rech, Schwade e Schwade (2013) constataram em seu estudo que as abelhas da espécie D. ghilianii, além de serem resistentes ao ataque de Lestrimelitta, apresentam um potencial na proteção de colônias de outras espécies.

Observou-se em todas as quatro semanas de estudo, que as abelhas colocaram pequenos pedaços de cera nas suas colmeias. Supõe-se que esse fato indica que as abelhas, além de terem aceitado bem sua nova casa, 
se revelam fortes, ou seja, com a rainha fisogástrica em plena atuação fazendo a coesão da colônia, e bem alimentadas.

\section{Conclusão}

1. Majoritariamente as abelhas Scaptotrigona postica da Zona da Mata Pernambucana (ZMP) têm preferência por nidificação, em colmeias octogonais ISA 2014, para as direções Noroeste (NO) e Oeste (O);

2. As abelhas $S$. postica iniciam o fechamento dos orifícios em colmeias ocotogonais nas coordenadas Nordeste (NE) e Sul (S) na ZMP;

3. A probabilidade de encontrar os orifícios abertos em colmeias octogonais é menor a cada dia após a instalação das famílias de $S$. postica;

4. As atividades das abelhas $S$. postica em relação ao fechamento dos orifícios não desejáveis em colmeias octogonais se acentuam nos períodos mais quentes do dia;

5. Os fatores abióticos do ambiente não influenciam na probabilidade de encontrar orifícios abertos em colmeias octogonais contendo abelhas S.postica;

6. A probabilidade de encontrar os orifícios abertos em colmeias octogonais, quando há incidência de vento, é maior para o Leste (L) e Sudeste (SE).

\section{REFERÊNCIAS}

Aquino IS. 2006. Abelhas Nativas da Paraíba. 1ª ed., João Pessoa: Editora Universitária/UFPB, 91 p.

Araújo JF, Marques N. 2002. Cronobiologia: uma Multidisciplinaridade necessária. MARGEM, SÃO PAULO, 15:95-112. Disponível em: http://www.pucsp.br/margem/pdf/m15jn.pdf Acesso em: 09 Nov. 2016.

Aragão PHA. 1985. Orientação pelo Campo Geomagnético. Semina, 6(2):93-97.

Almeida GF. Fatores que interferem no comportamento enxameatório de abelhas africanizadas. 2008. Tese (Doutorado em Ciências) Universidade de São Paulo-USP, Ribeirão Preto-SP, 128 p.

Chin-Yuan H. et al. 2007. Magnetoreception system in Honeybees (Apis mellifera). Plos One, 2 (4):395.

CONAMA. Conselho Nacional do Meio Ambiente. RESOLUÇÃO CONAMA no 346, de 16 de agosto de 2004, publicada no DOU nº 158, de 17 de agosto de 2004, Seção 1, página 70. Disciplina a utilização das abelhas silvestres nativas, bem como a implantação de meliponários. Disponível em: http://www.mma.gov.br/port/ conama/legiabre.cfm?codlegi=448 Acesso em: 04 Nov. 2016.

Coletto-Silva A. 2005. Captura de Enxames de Abelhas Sem Ferrão (Hymenoptera, Apidae, Meliponinae) sem Destruição de Árvores. Acta Amaz. [online], 35(3): 383-388. Disponível em: http://www.scielo.br/scielo. php?pid=S0044-59672005000300012\&script=sci_abstract\&tlng=pt Acesso em: 06 Nov. 2016.

Chagas F, Carvalho S. 2005. Iniciação à Criação de Uruçu. Meliponário São Saruê, Igarassu-PE, 2nd ed., 50 p. 
Esquivel DMS. et al. 2007. Do geomagnetic storms change the behaviour of the stinglessbee guiruçu (Schwarzianaquadripunctata)?. Naturwissenschaften, Springer Science e Business Media B., 94(2):139-142.

Ferreira RP. Influência da orientação, sombreamento e substrato de ninhos armadilha na captura de espécies de abelhas e vespas nidificantes em cavidades preexistentes. 2009. Dissertação (Mestrado em Ciências Biológicas). Universidade Federal da Paraíba-UFPB, 56 p.

García BMP. Ritmos Circadianos y Neurotransmisores: EstudiosenlaCortezaPrefrontal de la Rata. 2004. Tese (Doutorado em Ciências Biológicas). UniversidadComplutense de Madrid, Madrid-Brasil, 194 p.

Gonçalves RC, Marques MD. 2012. Ritmos de populações: o caso das abelhas sem ferrão. Revista da Biologia, 9(3):53-57.

GOOGLE. Google Earth. 7.1.7.2606 X 2016. Experimento (propriedade São Saruê, município de Igarassu$\mathrm{PE})$.

Hilário SD, Ribeiro MF, Imperatriz-Fonseca VL. 2007. Efeito do vento sobre a atividade de vôo de Plebeia remota (Holmberg, 1903) (Apidae, Meliponini). Biota Neotrop., 7(3): 225-232.

Kirschvink JL, GOULD JL. 1980. Biogenic magnetite as a basis for magnetic field detection in animals. Biosystems, Elsevier/North-Holland, Scientific Publishers Ltda, 13:181-201.

Kirschvink JL. et al. 1997. Measurement of the Threshold Sensitivity of Honeybees to Weak, Extremely LowFrequency Magnetic Fields. The Journal of Experimental Biology, 200:1363-1368.

Kirschvink JL, Winklhofer M, WALKER MM. 2010. Biophysics of magnetic orientation: strengthening the interface between theory and experimental design. J. R. Soc. Interface, 7:179-191.

Keim CN. et al. 2000. Ferritin in iron containing granules from the fat body of the honeybees Apismellifera and Scaptotrigonapostica. Elsevier Science Ltd. Allrightsreserved, Micron, 33:53-59.

Kerr WE, Carvalho GA, Nascimento VA. 1996. Abelha Uruçu: Biologia, Manejo e Conservação. Belo Horizonte, MG: Acangaú.

Lucano MJL. Centro Brasileiro de Pesquisas Físicas Rio de Caracterização de material magnético mineralizado em abelhas meliponini Schwarziana quadripunctata: magnetometria SQUID e Ressonância Ferromagnética. 2006. Tese de Doutorado, Centro Brasileiro de Pesquisas Físicas, Rio de Janeiro, 148 p.

Macieira OJD, Proni E. A. 2004. Capacidade de resistência a altas e baixas temperaturas em operárias de Scaptotrigonapostica (Latreille) (Hymenoptera, Apidae) durante os períodos de verão e inverno. Rev. Bras. Zool. Curitiba, 21(4):893-896.

Maschio DA, Gracioli-Vitti LF, Cruz-Landim C. 2012. Comparative study of intramandibular glands of workers, queens and males of stingless bee Scaptotrigona postica Latreille (Hymenoptera: Meliponini). Animal Biology, Koninklijke Brill NV, Leiden, 63:21-31. 
Moro VL. et al. 2012. Influência dos ritmos circadianos na temperatura corporal, no sistema cardiovascular, no desempenho psicomotor e neuromuscular. Rev Anda 1Med Deporte, 5(1):12-17.

Nogueira-Neto P. 1997. Vida e Criação de Abelhas indígenas sem ferrão. São Paulo: Editora Nogueirapis, n. 77, v. 8,445 p.

Oliveira FF. et al. 2013. Guia Ilustrado das Abelhas “Sem-Ferrão” das Reservas Amanã e Mamirauá, Brasil (Hymenoptera, Apidae, Meliponini). Tefé: IDSM. 267 p.

Oliveira FL. et al. 2012. Influência das variações climáticas na atividade de vôo das abelhas jandairas Melipona subnitida Ducke (Meliponinae). Revista Ciência Agronômica, 43(3):598-603.

Ramos M. et al. 2007. Nidificação e forrageamento de Centris (Ptilotopus) maranhensis Ducke (Hymenoptera, Apidae, Centridini). Revista Brasileira de Zoologia, 24(4):1006-1010.

Rech AR, Schwade MA, Schwade MR. 2013. Abelhas-sem-ferrão amazônicas defendem meliponários contra saques de outras abelhas. Acta Amaz: [online], 43(3):389-394. Disponível em: http://www.scielo.br/scielo. php?pid=S0044-59672005000300012\&script=sci_abstract\&tlng=ptv. Acesso em: 10 Dez. 2016.

SAS. Base SAS ${ }^{\circledR}$ 9.3 Procedures Guide: Statistical Procedures. 2ª ed. Cary: SAS Institute Inc., 2012.

Santos TCA, Cruz-Landim C. 2002. Determinação das castas em Scaptotrigona postica (Latreille) (Hymenoptera, Apidae, Meliponini): diferenciação do ovário. Revista bras. Zool, 19(3):703-714.

Silva FJA. Preferência de Nidificação em Abelhas Indígenas. 2016. Dissertação (Mestrado em Ciências Agrárias “Agroecologia”). Universidade Federal da Paraíba-UFPB, Bananeiras-PB, 90 p.

Schiff H. 1991. Modulation of Spike Frequencies by Varying the Ambient Magnetic Field and Magnetite Candidates in Bees (Apis Mellifera). Camp. Eiochem. Phystol, 100(4): 975-985.

Souza HRA. et al. 2015. Espectro polínico da própolis de Scaptotrigona aff. postica (Hymenoptera, Apidae, Meliponini) em Barra do Corda, MA, Brasil. Acta Amaz, Manaus, 45(3):307-316.

Vaz MA. Influência dos Pontos Cardeais e Colaterais na Nidificação De Abelhas Nativas. 2015. Dissertação (Mestrado em Ciências Agrárias “Agroecologia”). Universidade Federal da Paraíba-UFPB, 36 p.

Villas-Bôas J. 2012. Manual Tecnológico: Mel de Abelhas sem Ferrão. Brasília-DF. Instituto Sociedade, População e Natureza (ISPN). Brasil. Disponível em: http://www.ispn.org.br/arquivos/mel008 31.pdf Acesso em: 04 Nov. 2016.

Venturieri GC. 2008. Criação de abelhas indígenas sem ferrão. 2nd ed., rev. atual. Belém, PA: Embrapa Amazônia Oriental, 60 p.

Witter S. 2014. Manual de boas práticas para o manejo e conservação de abelhas nativas (meliponíneos). 1. ed. Porto Alegre: Fundação Zoobotânica do Rio Grande do Sul, 141p.

Wajnberg E. et al. 2010. Magnetoreception in eusocial insects: an update. J. R. Soc. Interface, 7:207-225. 